\title{
KEANEKARAGAMAN JENIS KELELAWAR DI KAWASAN CAMP LUBUK BAJI TAMAN NASIONAL GUNUNG PALUNG
}

\author{
(Bats Species Diversity in Camp Lubuk Baji Gunung Palung National Park)
}

\author{
Naszami, M. Sofwan Anwari, Slamet Rifanjani \\ Fakultas Kehutanan Universitas Tanjungpura Pontianak, Jl. Daya Nasional Pontianak 78124 \\ Email: jimy.perantau@gmail.com
}

\begin{abstract}
Bat is one of the important components in the stability of the ecosystem. One of the their role helping the spread of the seeds and flower pollination and insect population control. The presence of bats in the area of Camp Lubuk baji National Park (TNGP) have an important role in the forest regeneration and ecosystem stability. Until now the availability of information about the diversity of species bat in the TNGP still not provided and so potential unknown. This report aims to review the diversity of species bat in the area of Gunung Palung National Park. This research was aiming to discover the diversity of types of bats in the area Gunung Palung National Park. This research uses method capture with mist net. The placement of the research carried out observing the traffic line bat purposive. Mist net placed on three layer of tree canopies of the flower layer, middle, and the upper layer headers tree. The research conducted 2 in location Camp Lubuk Baji and Batu Bulan. The result show abot his Camp Lubuk Baji index of 0,24 dominance, while index in the Batu Bulan of 0,46. The diversity of species closer to the bottom of Camp Lubuk Baji 1,37, while in the Batu Bulan of 0,90. The kind of evenness Batu Bulan of 0,81, while in his 0,76 Camp Lubuk Baji. Similarity in type of closer to Camp Lubuk Baji bottom and rock Batu Bulan having index 0,53 or 53\%.
\end{abstract}

Keywords: Batu Bulan, Bats diversity, Camp Lubuk Baji

\section{PENDAHULUAN}

Ekosistem TNGP merupakan ekosistem hutan hujan tropis yang masih asli dan kaya akan jenis-jenis satwa dan tumbuhan. Potensi flora dan fauna tersebut belum seluruhnya terdokumentasikan secara baik untuk mendukung pengelolaan TNGP. Salah satu potensi keanekaragaman hayati yang ada adalah kelelawar (Chiroptera). Kelelawar sebagai salah satu jenis satwa yang menempati ekosistem hutan memiliki fungsi ekologis yang penting bagi kelestarian hutan. Kelelawar bermanfaat sebagai pengendali populasi serangga. Berdasarkan penelitian diperkirakan $95 \%$ dari regenerasi hutan di lakukan oleh kelelawar jenis pemakan buah dan biji (Satyadarma, 2005).

Kelelawar merupakan salah satu komponen penting dalam kestabilan ekosistem. Salah satu peranannya membantu penyebaran biji dan penyerbukan bunga serta pengendali populasi serangga, sehingga kelelawar memiliki arti penting secara ekologis, keberadaan kelelawar di kawasan Camp Lubuk Baji Taman Nasional Gunung Palung (TNGP) memiliki peranan penting dalam regenerasi hutan dan menjaga kestabilan ekosistem. Sampai 
saat ini ketersediaan informasi mengenai keanekaragaman jenis kelelawar di TNGP masih belum tersedia sehingga potensinya belum diketahui. Penelitian ini bertujuan untuk mengetahui keanekaragaman jenis kelelawar di kawasan Taman Nasional Gunung Palung.

\section{METODE PENELITIAN}

Penelitian ini dilakukan pada bulan Juni sampai dengan Juli 2018 di kawasan Taman Nasional Gunung Palung yang berada di Desa Sedahan Jaya, Kecamatan Sukadana, Kabupaten Kayong Utara. Alat dan bahan yang digunakan dalam penelitian ini adalah GPS, Mist net, Caliper, Kamera, Pegas 100 gr, Sarung tangan, Gunting, Head Lamp dan senter.

\section{Analisi Data.}

1. Indeks Dominansi

(Simpsons

Indeks) / (C)

Untuk mengetahui dominansi suatu jenis yang terpusat dalam komunitas digunakan rumus (Odum, 1993).

$$
C=\sum\left[\frac{n i}{N}\right]^{2}
$$

Dimana:

$$
\begin{array}{ll}
\mathrm{C}= & \text { Indeks Dominansi (Simpsons } \\
& \text { Indeks }) \\
\mathrm{ni}= & \text { Jumlah individu suatu jenis } \\
\mathrm{N}= & \text { Jumlah individu seluruh jenis }
\end{array}
$$$$
\text { Nilai indek berkisar antara 0-1 }
$$

$\mathrm{C}=0$, berarti tidak terdapat jenis yang mendominasi jenis lain

$\mathrm{C}=1$, berarti terdapat jenis yang mendominansi jenis lain

2. Indeks Keanekaragaman Jenis $(\mathrm{H})$

Untuk mengetahui keanekaraman jenis dalam suatu komunitas digunakan Indeks Keanekaragaman Shannon
(Shannon-wiener), dengan rumus (odum,1993) dengan rummus sebagai berikut:

$\mathrm{H}^{\prime}=-\sum$ pi Ln pi

Keterangan:

$\mathrm{H}^{\prime} \quad$ = Indeks keanekaragaman jenis

$\mathrm{Pi}=$ Jumlah proporsi kelimpahan satwa spesies $\mathrm{i}$

$\mathrm{N} \quad=$ Total jumlah individu seluruh jenis

$\mathrm{Ni}=$ Jumlah individu tiap jenis

Ln = Logaritma natural

Kriteria nilai indeks keanekaragaman Shannon - Wiener $\left(H^{\prime}\right)$ adalah sebagai berikut:

$H^{\prime}<1 \quad$ :keanekaragaman rendah $1<H^{\prime} \leq 3 \quad$ :keanekaragaman sedang H'> 3 :keanekaragaman tinggi

3. Indeks Kemerataan ( Indeks Evenness) / ( e )

Adalah untuk mengetahui tingkat kelimpahan suatu jenis yang dipengaruhi oleh keragaman atau nilai kemerataan di antara jenis yang ada dalam suatu komunitas. Digunakan Pielau (1996) dalam Odum (1993) yaitu sebagai berikut:

$$
\mathrm{E}=\mathrm{H}^{\prime} / \log \mathrm{S}
$$

Keterangan:

H' : Indeks Shannon

S : Jumlah spesies

E : Indeks kemerataan

Kriteria nilai komunitas berdasarkan kemerataan:

$0,00<\mathrm{E}<0,50$ : Komunitas Tertekan

$0,05<\mathrm{E}<0,75 \quad$ : Komunitas labil

$0,75<\mathrm{E}<1,00 \quad$ : Komunitas stabil

4. Indeks Kesamaan Jenis (Indek Sorensent) 
Untuk mengetahui besarnya indeks kesamaan dapat digunakan rumus sebagai berikut:

$$
I S=\frac{2 C}{A+B} \times 100 \%
$$

Keterangan:

IS : indeks kesamaan

$\mathrm{C}$ : jumlah spesies yang sama dan terdapat pada kedua komunitas

A : jumlah spesies di dalam komunitas A

B : jumlah spesies di dalam komunitas B

Kriteria indeks kesamaan jenis yaitu, jika IS mendekati 100\% maka tingkat kesamaan tinggi.
HASIL DAN PEMBAHASAN Jenis kelelawar di Camp Lubuk Baji

Hasil penelitian di kawasan Camp lubuk Baji (TNGP), Desa Sedahan Jaya Kecamatan Sukadana Kabupaten Kayong Utara, pada lokasi sekitar Camp yaitu diketahui terdapat 3 family, 6 jenis kelelawar dengan total individu sebanyak 104 ekor. Berdasarkan jenis pakannya, terdapat 2 jenis Megachiroptera dan 2 jenis Microchiroptera. Individu berkelamin jantan 66 ekor $(63,46 \%)$ dan betina 38 ekor $(36,54 \%)$.

Tabel 1. Jenis Kelelawar di kawasan Camp Lubuk Baji dan Batu Bulan (Bats diversity in Camp Lubuk Baji and Batu Bulan)

\begin{tabular}{|c|c|c|c|c|c|}
\hline No & Sub Ordo & Family & Jenis & $\begin{array}{l}\text { Lubuk } \\
\text { Baji }\end{array}$ & Batu Bulan \\
\hline \multirow[t]{4}{*}{1.} & Megachiroptera & pteropodidae & $\begin{array}{l}\text { Dyacopterus } \\
\text { spadeceus }\end{array}$ & 30 & 0 \\
\hline & & & $\begin{array}{l}\text { Chynopterus } \\
\text { brachyotis }\end{array}$ & 23 & 5 \\
\hline & & & $\begin{array}{l}\text { Balionycteris } \\
\text { maculate }\end{array}$ & 0 & 1 \\
\hline & & & $\begin{array}{l}\text { Macroglossus } \\
\text { minimus }\end{array}$ & 0 & 2 \\
\hline \multirow[t]{2}{*}{2.} & Microchiroptera & hipposideridae & $\begin{array}{l}\text { Hipposideros } \\
\text { cervinus }\end{array}$ & 18 & 0 \\
\hline & & Megadermatidae & $\begin{array}{l}\text { Megaderma } \\
\text { pasma }\end{array}$ & 25 & 0 \\
\hline
\end{tabular}

Hasil penelitian menunjukan jumlah dan jenis kelelawar menunjukan perbedaan pada setiap lokasi penelitian di Kawasan Camp Lubuk Baji Taman Nasional Gunung Palung. Perbedaan di karenakan setiap lokasi memiliki kondisi habitat yang berbeda dan gangguan berbeda di sekitar kawasan. Lokasi di Camp Lubuk Baji gangguan habitatnya relative kecil, memiliki jumlah dan jenis Kelelawar lebih tinggi di bandingkan dengan Batu Bulan. Hal ini sesuai dengan pernyataan Alikodra (1979) yang menyatakan bahwa kualitas dan kuantitas akan menentukan suatu komposisi, penyebaran, dan produktivitas makhluk hidup.

\section{Morfologi Kelelawar}

Morfologi kelelawar di kawasan Camp Lubuk Baji Taman Nasional 
Gunung Palung, dari hasil pengukuran 7 jenis kelelawar, 5 jenis Megachiroptera dan 2 jenis Microchiroptera, dapat dilihat pada tabel berikut:

Tabel 2. Morfometri Kelelawar (Bats Morphometry)

Jenis Morfologi tubuh kelelawar

\begin{tabular}{lllllllll} 
& LB & & E & & T & \multicolumn{2}{c}{ BR } \\
\hline & Payne* & Penelitian & Payne* & Penelitian & Payne* & Penelitian & Payne* & Penelitian \\
\hline Megaderma pasma & $54-61$ & $51-57$ & - & - & - & $54,2-60,6$ & - & 21 \\
Dyacopterus spadiceus & $78-81$ & $71-85,3$ & $19-24$ & $19-20$ & $17,5-21$ & $14-18,3$ & $75-100$ & $70-94$ \\
Chynopterus brachyotis & $55-66$ & $52-65$ & $9-10$ & $3,5-17$ & $14-17$ & $9,5-26,5$ & $21-32$ & $19-36$ \\
Hipposideros cervinus & $44-50$ & 49 & $21-28$ & 27 & $14-17$ & 16,5 & $7-10$ & 9 \\
Balionycteris maculate & $40-45$ & $30-42,5$ & - & - & $10-12$ & $6,3-13,3$ & $10-15$ & $6-14$ \\
Macroglossus minimus & $38-42$ & 43 & - & - & $13-15,5$ & 10,6 & $11-16$ & 17 \\
\hline
\end{tabular}

*Payne et al. (2000)

Indeks Dominansi (C), Indeks Keanekaragaman (H), dan Indeks Kemerataan (e), dan Kesamaan Jenis kelelawar di kawasan Camp Lubuk Baji dan Batu Bulan TNGP.

Hasil analisa data menunjukan bahwa tidak terdapat jenis kelelawar yang mendominansi pada ke dua lokasi penelitian di kawasan Camp lubuk baji TNGP, dimana pada setiap lokasi memiliki indeks dominansi lebih kecil dari 1(satu). Indeks dominansi kelelawar tertinggi pada Batu Bulan dengan indeks yaitu dengan besaran 0,76605. Kesamaan Jenis di kawasan Camp Lubuk Baji dan Batu Bulan. (index Dominance, index Diversity of species, Equity index, and Similarity index)

\begin{tabular}{lllll}
\hline $\begin{array}{l}\text { Lokasi } \\
\text { Penelitian }\end{array}$ & $\mathrm{C}$ & $\mathrm{H}$ & $\mathrm{E}$ & IS (\%) \\
\hline Lubuk Baji & 0,249 & 1.370071 & 0,76605 & \\
& & & & $53 \%$ \\
Batu Bulan & 0,4687 & 0,90026 & 0,81945 & \\
\hline
\end{tabular}

\section{Sumber Analisa data 2018}

Hasil analisa data menunjukan tidak adanya dominansi jenis kelelawar dari kedua lokasi penelitian di kawasan Camp Lubuk Baji. Pada ke dua lokasi indeks dominansi relative hampir sama, dengan nilai indeks sama dengan 0 (nol). Indeks

sebesar 0,4687 dan indeks dominansi terendah pada sekitar Camp Lubuk Baji yaitu sebesar 0,249.Keanekaragaman jenis kelelawar di Kawasan Camp Lubuk Baji TNGP relative lebih besar yaitu 1.370071 dan keanekaragaman jenis paling rendah terdapat di Batu Bulan yaitu sebesar 0,90026. Indeks kemerataan jenis yang paling tinggi berada pada Batu Bulan dengan besaran yaitu 0,81945 dan untuk indeks kemerataan yang paling rendah terdapat pada kawasan Camp Lubuk Baji yaitu dengan besaran 0,76605. karagaman, Indeks Kemerataan, Indeks Lokasi dominansi suatu jenis yang terpusat dalam komunitas dapat diketahui dengan nilai $\mathrm{C}=$ 0 , berarti tidak terdapat jenis yang mendominansi jenis lainnya, sedangkan $\mathrm{C}=1$, berarti terdapat jenis mendominansi jenis lainnya. Pada lokasi Camp Lubuk 
Baji nilai indek dominansi sebesar 0,249, sedangkan pada lokasi batu Bulan 0,4687, artinya tidak terdapat jenis yang mendominansi pada kedua lokasi penelitian. Indeks keanekaragaman jenis kelelawar di Kawasan Camp Lubuk Baji tergolong sedang dengan besaran sekitar 1,370071, sedangkan keanekaragaman jenis kelelawar pada Batu Bulan sangat rendah dengan besaran0,90026. Indeks keanekaragaman suatu jenis dalam komunitas memiliki nilai indek $H^{\prime} \leq 1$ berarti keanekragaman tersebut rendah, apabila $1<H^{\prime} \leq 3$ berarti keanekaragaman tersebut sedang, dan apabila $H^{\prime} \geq 3$, berarti keanekaragaman tersebut tinggi. Pada lokasi Camp Lubuk Baji keanekaragaman tergolong sedang dengan nilai indek sebesar 1,370071, sedangkan pada lokasi Batu Bulan indek keanekaragaman tergolong rendah dengan nilai indek sebesar 0,90026. Indek kemerataan untuk mengetahui kelimpahan suatu jenis yang dipengaruhi oleh keragaman atau nilai kemerataan di antara jenis yang ada dalam suatu komunitas dengan nilai $0,00 \leq \mathrm{E} 0,50$ yang artinya kemerataan sautu jenis tertekan, sedangkan $0,05 \leq \mathrm{E} \leq 0,75$ berarti kemerataan atau komunitas labil, dan $0,75 \leq \mathrm{E} \leq 100$ berarti komunitas stabil. Pada lokasi Camp Lubuk Baji kemerataan tergolong labil dengan indek sebesar 0,76605, dan pada lokasi Batu Bulan kemerataan tergolong stabil dengan nilai indek sebesar 0,81945.

Pada lokasi kawasan Camp Lubuk Baji dan Batu Bulan kesamaan jenis kelelawar relatife rendah. Kesamaan jenis pada lokasi penelitian Camp Lubuk Baji dan Batu Bulan memiliki indeks sebesar
53\%. Berdasarkan analisa penelitian menunjukan kesamaan jenis kelelawar di kawasan Camp Lubuk Baji relatife rendah. Hal ini disebabkan karena hanya jenis Codot Krawar (Cynopterus brachyotis) terdapat pada dua lokasi penelitian. Banyaknya kelelawar pada kawasan Camp Lubuk Baji sebanyak 96 ekor, sedangkan pada lokasi Batu Bulan sebanyak 8 ekor saja.

Hal ini sesuai dengan pernyataan dari Martin (2008) bahwasanya salah satu fungsi dari fungsi hutan adalah sebagai penyangga dan koridor loncatan (Sleeping stone coridor) satwa liar dari hutan dan ke hutan. Boughey (1973) mengatakan pergerakan satwa erat kaitannya dengan persediaan makanan, fasilitas untuk berkembang biak, kondisi iklim atau cuaca, pemangsa sumber air, mereka bergerak untuk mencari makan, untuk hidup dan berkembangbiak dengan baik. Alikodra (1979) mengatakan jenis yang banyak melakukan pergerakan berarti jenis tersebut dapat menggunakan lebih dari satu tipe habitat.

\section{Kesimpulan}

1. Jumlah kelelawar yang tertangkap pada dua lokasi penelitian di kawasan Camp Lubuk Baji TNGP sebanyak 104 individu tergolong 2 family, 7 jenis kelelawar. Individu berkelamin jantan sebanyak 66 ekor $(63,46 \%)$ dan betina 38 ekor $(36,54 \%)$.

2. Keanekaragaman jenis kelelawar pada dua lokasi masih tergolong rendah. Keanekaragaman jenis tertinggi dengan indeks 1,370071. Indeks keanekaragaman jenis terendah sebesar 0,90026. 
3. Kemerataan jenis kelelawar di kawasan Camp Lubuk Baji TNGP masih tergolong rendah. Kemerataan jenis kelelawar tertinggi dengan indeks kemerataan jenis sebesar 0,81945 , dan kemerataan jenis terendah dengan indeks sebesar 0,76605.

4. Pada setiap tipe hutan di kawasan Camp Lubuk Baji TNGP, tidak terdapat jenis kelelawar yang mendominasi jenis lainnya. Indeks Dominansi tertinggi dengan indeks 0,4687. memiliki sedangkan indeks dominansi terendah dengan indeks 0,249 .

5. Berdasarkan analisa penelitian menunjukan kesamaan jenis kelelawar di kawasan Camp Lubuk Baji relative rendah dengan indeks sebesar 0.53846 . Hal ini disebabkan karena hanya jenis Codot Krawar (Cynopterus brachyotis) terdapat pada dua lokasi penelitian.

\section{Saran}

1. Penelitian ini merupakan langkah awal dalam mempelajari kebaradaan jenis kelelawar di Kawasan Camp Lubuk Baji Taman Nasional Gunung Palung (TNGP), sehingga diperlukan penelitian lebih lanjut terhadap peran kelelawar dalam menjaga keseimbangan ekosistem di TNGP.

2. Untuk mengetahui penyebaran jenis kelelawar di daerah koridor TNGP khususnya kawasan Camp Lubuk Baji dan diperlukan penelitian jenis kelelawar pada lokasi lain dengan kondisi habitat yang berbeda.

3. Keadaan Taman Nasional Gunung Palung yang telah mengalami gangguan sehingga diperlukan upaya penanggulangan dari pihak berwenang terhadap aktifitas penebangan illegal dan pembakaran lahan guna menjaga kondisi kawasan agar kelestarian kelelawar tetap terjaga.

\section{DAFTAR PUSTAKA}

Satyadharma A. 2005. Hidup Bersama Kelelawar. Jurnal Tropika Indonesia. Edisi Juli-Desember VOL. 9 No.3-4. Jakarta

Odum E P. 1993. Dasar-Dasar Ekologi. Edisi Ketiga. Gajah Mada University. Yogyakarta

Alikodra H S. 1979. Dasar-Dasar Pembinaan Margasatwa. Fakultas Kehutanan Institut Pertanian Bogor. Bogor.

Meijaard E. Douglas S, Robert N, David A, Barry R, Djoko I, Titiek S., MartjanL, Ike R, Anna W, Tonny S, Scoot S, Tiene G, dan Timothy O. 2006. Hutan Pasca Pemanenan, Melindungi Satwa Liar Dalam Kegiatan Hutan Produksi Di Kalimantan. Center For International Forestry Research. Jakarta.

Boughey A S. 1973. Ecology of Population. Second Edition. Mac Millan Publising co. Inc, New York.

Elangovan, V. and Marimuthu, G. (2001), Effect of moonlight on the foraging behavior of a megachiropteran bat cynopterus sphinx. Journal of Zoology, 253: 347-350.

Payne, J, Francis, CM, Philip, K \& Kartikasari, SN,2000,Panduan lapangan mamalia di Kalimantan, Sabah, Sarawak, \& Brunei Darussalam, WCS Indonesia program, Bogor. 